\title{
Effects of Biological Crust on Soil Properties under Different Karst Rocky Desertification Habitats
}

\author{
Zhiheng Zheng ${ }^{1}$, Kangning Xiong ${ }^{1 *}$, Li Rong ${ }^{2}$, Yongkuan Chi ${ }^{1}$
}

${ }^{1}$ School of Karst Science, Guizhou Normal University/State Engineering Technology Institute for Karst Desertification Control, No. 116 Baoshan North Road, Yunyan District, Guiyang City, Guizhou Province 550001, China ${ }^{2}$ School of Geography and Environmental Science, Guizhou Normal University, No. 116 Baoshan North Road, Yunyan District, Guiyang City, Guizhou Province 550001, China

Received: 31 August 2020

Accepted: 10 November 2020

\begin{abstract}
Biological crust is an important type of surface cover in karst ecosystems and plays a key role in the restoration of rocky desertification and ecological control projects. It is very important to study the influence of different types of biological crust on the physical and chemical properties of subsoil under different levels of rocky desertification to explore the formation and development of soil in karst ecologically fragile areas and the stability of soil environment. In the crust layer, total nitrogen, available nitrogen, total phosphorus, available phosphorus, available $\mathrm{k}$, soil organic carbon, soil field capacity and soil porosity manifest as moss crusts $>$ mixed biocrust $>$ lichen biocrust $>$ algae biocrust $(P<0.05)$, while soil bulk density manifests as algal crust $>$ lichen crust $\geq$ mixed crust $\geq$ mossy crust $(P>0.05)$. The physical and chemical properties of $0-5 \mathrm{~cm}$ and $5-10 \mathrm{~cm}$ soil layers on the subcutaneous surface of biological nodules are similar to those of the crust laye. biological crusts have an impact on the improvement of physical and chemical properties of the underlying soil in the latent, mild and moderate-intense rocky desertification areas, that is the moss crust and mixed crust are greater than lichen crust and algae crust and the influence of different types of biological crust on the physical and chemical properties of the underlying soil decreases with the deepening of the soil layer. Besides $\mathrm{pH}$ value, soil physical and chemical properties (total nitrogen, available nitrogen, available potassium, total phosphorus, available phosphorus, soil organic carbon, soil bulk density, soil field capacity, soil porosity and available potassium) of different types of BSCs are significantly correlated. Biological crust is a good prerequisite for the growth and development of vegetation as it can significantly improve the physical and chemical properties of soil, increase soil nutrient content, promote the formation of soil aggregates, enhance the bearing capacity and anti erosion capacity of land, and balance the stability of soil environment. Therefore, it is of great significance to study the mechanism of biological crust on soil physical and chemical properties improvement and the interaction mechanism between biological
\end{abstract}

*e-mail: xiongkn@163.com 
crust and soil environment in karst rocky desertification area for the study of biodiversity construction, material and energy cycle path, nitrogen deposition, carbon sink effect and rocky desertification control measures.

Keywords: biological crust, physical and chemical properties of soil, karst areas, rocky desertification, the soil environment

\section{Introduction}

Biological soil crust (BSC), a surface complex formed by mycelium secreted polysaccharides from mycelia of cryptoflowering plants such as fungi, algae, lichens, and mosses, and cemented soil grains, is an important part of the ecosystem [1]. With its unique physiological structure and strong adaptation mechanism, BSCs are widely distributed in harsh habitats such as rocky desertification, desertification and polar regions. The succession development of BSCs plays an important role in the formation process of soil as it can effectively improve soil structure and physical and chemical properties, improve soil stability and productivity, reduce soil erosion, and effectively prevent and control geological disasters to a certain extent [2]. It also helps promote the cycle and accumulation of material and energy in the soil environment, regulate the hydrological process, and further promote the developmental succession of vegetation and improve biodiversity. As there are different mother rock matrixes, the community structure of BSCs differs with each other, and the community heterogeneity and ecological factors have also their own features. Many factors also have a certain impact on the physiological indexes and ecological groups such as the species composition, plant height, individual density, vegetation coverage and so on of BSCs [3]. Research reports on BSCs in the karst region show that crust vegetation widely exists in the surface layer of all types of soil in the geomorphic area, and the composition of BSCs community is different under different rocky desertification microhabitats [4-5].

Rocky desertification, a land degradation, is a stony desertification landscape in karst areas, which is formed by time-honored parent rock formation, poor soil, high exposure of bedrock and low vegetation coverage overlaid with undue human behaviors [6]. Researchers divided the karst rocky desertification levels into six grades: no rocky desertification, potential rocky desertification, mild rocky desertification, moderate rocky desertification, intense rocky desertification and extremely intense rocky desertification in the light of the indicators such as the degree of rock exposure, vegetation coverage and biodiversity [7]. Among them, the physical and chemical properties of soil, the key factors to reflect the soil quality, are of great significance to the studies on the conservation of soil environmental material and energy, the coupling mechanism between habitats and the construction of biodiversity in karst rocky desertification areas. BSCs, with good stress tolerance, strong stress resistance, high compatibility with different habitats, and good adaptability to karst ecosystems, are important surface cover vegetation in karst rocky desertification areas [8].

At present, although there are some reports about research of soil physicochemical properties generated by BSCs, there is still a lack of research on biological crust in karst rocky desertification area, which mainly restricted on the basic research of some functional characteristics such as the classification and composition of BSCs community, the analysis of succession habits, and the water holding capacity and soil forming capacity of plants [9]. Therefore, this study, researching the different grades of rocky desertification in the plateau mountain area made of latent-mild rocky desertification and the plateau canyon area mainly consisting of moderate-intense rocky desertification, systematically analyzes the impact of biological crust on 10 key physical and chemical indicators of soil (soil chemical indicators: $\mathrm{pH}$ value, total nitrogen, available nitrogen, total phosphorus, available phosphorus, fast speed), and explores the interaction mechanism between BSCs and soil environment in quest of enlightening the research on the coupling mechanism between karst habitats so as to provide scientific basis for further research on the ecological restoration model of stony desertification.

\section{Materials and Methods}

\section{Overview of the Research Area}

In this study, Guizhou rocky desertification region, which is the most representative karst rocky desertification area in southern China, is selected as the research area. The research area I is the typical latent mild rocky desertification area of Salaxi karst plateau in Bijie (hereinafter referred to as Salaxi research area), and the research area II is the typical area of moderateintense rocky desertification in Guanling Zhenfeng Huajiang karst plateau Canyon (hereinafter referred to as Huajiang research area).

The research area I (Table 1), a plateau mountainous area with an average altitude of 1410-1780 m with broken and undulating terrain, is located in Salaxi Town, Bijie City, Guizhou Province (271' $30^{\prime \prime}$ $\left.-27^{\circ} 16^{\prime} 50^{\prime \prime} \mathrm{N}, \quad 105^{\circ} 03^{\prime} 10^{\prime \prime}-105^{\circ} 05^{\prime} 08^{\prime \prime} \mathrm{E}\right)$. There, with over 245 days of frost free, enjoys an average annual precipitation $900 \mathrm{~mm}$, more than $50 \%$ of which is from June to October. The rock in the area is mainly carbonate limestone, and the soil is yellow soil and purple sand soil. The latent and mild rocky 


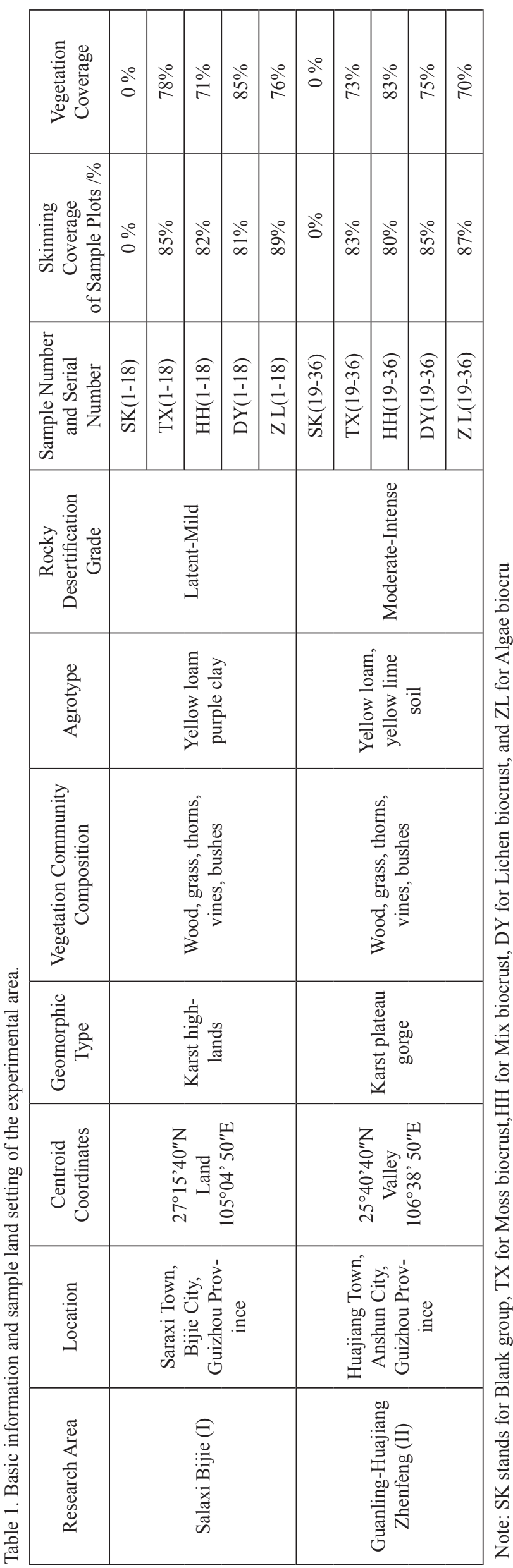

desertification area accounts for more than $68.65 \%$ of the total area [10]. The wild vegetation there includes grass, thorns, vines, bushes formed by Millettia pachycarpa, Pyracantha angustifolia, Rosa roxbunghii, Pennisetum hydridum, Pennisetum alopecuroides, Lolium perenne, etc., and scattering woods like Pinus massoniana and Populus Adenopoda, Rhododendron simsii, Betula luminifera, etc. In this research area, algae, lichens, mixed and bryophytic crust are distributed in different geomorphologic parts, and the total coverage of the crust is $86 \%$, among which the coverage of algae, lichens, mixed and bryophytic crust are $11 \%, 14 \%, 23 \%$ and $38 \%$, respectively. The algae in biological crusts are mainly Scy-tonema Javanicum, Microcoleus vaginatus, Lyngbya cryp-tovaginatus, etc. while Lichenes are mainly Dermatocarpon miniatum, Placidium squamulosum, Seirophora Contortuplicata, etc. And mosses mainly include Didymodonvinealis, Bryum Caespiticium, Weisia microstoma, Eurohypnum leptothollum, Hyophila involuta, Brachythecium plumosum, etc. [11].

The research area II (Table 1), a plateau canyon with dividing and undulating terrain of an average altitude of 450-1450 M, is located on both sides of the Canyon $\left(25^{\circ} 39^{\prime} 20^{\prime \prime}-25^{\circ} 41^{\prime} 20^{\prime \prime} \mathrm{N}, 106^{\circ} 37^{\prime} 30^{\prime \prime}-106^{\circ} 39^{\prime} 49^{\prime \prime} \mathrm{E}\right)$ at the junction of Guanling County, Anshun City, Guizhou Province and Zhenfeng County, Southwest Guizhou Province. The area, with more than 300 days of frost free, boasts an annual average precipitation $1100 \mathrm{~mm}$, more than $80 \%$ from May to October. The rocks are mainly carbonate limestone, and the soil are yellow soil and yellow lime soil. The area of moderate and strong rocky desertification accounts for $87.72 \%$ of the total area [12]. The wild vegetation is mainly grasses, thorns, vines, shrubs composed of Pyracantha angustifolia, Rosa roxbunghii, rubus corchorifolius, Pennisetum hydridum, Pennisetum alopecuroides, with scattered woods composed of Cupressus funebris, Broussonetia papyrifera and Pinus massoniana. In this research area, algae, lichens, mixed and bryophytic biodermatids are distributed in different landforms, and the total crust coverage is $82 \%$, among which $12 \%, 16 \%, 20 \%$ and $34 \%$, respectively, are algae, lichens, mixed and bryophytic. The algae in the biological crusts of this area mainly include Scy-Tonema Javanicum, Microcoleus Vaginatus, etc. The lichen is mainly composed of Seirophora Contortuplicata and Placidium squamulosum, etc., while moss mainly includes Didymodonvinealis, Bryum Caespiticium, Weisia microstoma and Eurohypnum leptothollum, etc. [13].

\section{Experimental Design and Sample Collection}

In this study, we selected typical algae crust (algae coverage $>80 \%$ ), lichen crust (lichen coverage $>80 \%$ ), mixed crust (moss, lichen and algae, accounting for 5:3:2) and moss crust (moss coverage $>80 \%$ ) in the research area as the research objects. In Salaxi demonstration area (I) and Huajiang demonstration 
area (II), three $15 \mathrm{~m} \times 15 \mathrm{~m}$ shrub quadrats and three $3 \mathrm{~m} \times 3 \mathrm{~m}$ herbaceous quadrats were set in each plot to investigate the community composition and coverage of shrubs and herbs. Finally, three experimental plots of $1 \mathrm{~m} \times 1 \mathrm{~m}$ blank group (bare land), algal crust, lichen crust, mixed crust and moss crust were selected in the area covered by BSCs between shrubs in the sample plot. Four kinds of BSCs group and the cortex under the blank group and three soil sample layers of $0 \sim 5 \mathrm{~cm}$ and $5 \sim 10 \mathrm{~cm}$ were selected by the S-type distribution. In September 2019, 45 physical and 45 chemical soil samples were collected in each research area, with a total of 180 mixed samples.

\section{Sample Treatment and Determination}

All soil samples were sealed with PE plastic bags and brought back to the laboratory for air drying. After removing the residual gravel and litter, the soil samples were passed through a $0.149 \mathrm{~mm}$ sieve to analyze its physical and chemical properties based on the standard soil analysis method in Soil Agrochemical Analysis [14].

1. Field water capacity was determined by gravimetric method

2. Soil bulk density in the junction layer was determined by membrane coating method, and soil bulk density and soil porosity in the sublayer was determined by ring knife method.

3. The content of soil organic carbon was determined by potassium dichromate oxidation-external heating method.

4. The total nitrogen was determined by perchloric acid-sulfuric acid boiling and Kjeldgren nitrogen determination method.

5. The available nitrogen was determined by alkaline hydrolysis diffusion method.

6. Total phosphorus was determined by perchloric acid, sulfuric acid desizing and molybdenum-antimony resistance colorimetric method.

7. The available phosphorus was extracted by ammonium fluoride and hydrochloric acid, and determined by molybdenum-antimony colorimetric method.

8. The determination of available potassium was made by ammonium acetate extraction at $1 \mathrm{~mol} \mathrm{pH} 7.0$ and flame photometry.

9. $\mathrm{PH}$ value was determined by a $5: 1$ soil/water ratio extraction.

10. The soil nutrient recovery index (RI) was used to calculate the differences of soil physical and chemical properties between the blank group and the blank group under the growth of BSCs. Finally, the differences of each attribute were summed and averaged to quantitatively describe the effect of different types of biological crusts on soil nutrient recovery. The calculation formula of soil restoration index [15].

$$
\left.R I=\frac{1}{n} \sum_{i=1}^{n}\left(\left(X_{i}-X_{i}^{\prime}\right) / X_{i}^{\prime}\right)\right) \times 100 \%
$$

Among them, $x_{i}$ is the ith soil attribute value under a certain type of BSCs, and $x^{\prime}$ is the ith soil attribute value of blank group.

\section{Data Processing}

Excel 2013 and SPSS 22.0 software were used for data processing and analysis. Single factor analysis of variance was used to compare the values of different types of BSCs and the physical and chemical properties of corresponding subsoil. The least significant difference (LSD) method was used for significance test $(\alpha=0.05)$. The physical and chemical properties of the subsoil of BSCs in different rocky desertification environments were analyzed by Peason correlation analysis, and the differences between BSCs and blank groups were compared, and the soil nutrient recovery index was calculated. In this study, Origin 2018 and Adobe Photoshop CS6 software were used for mapping.

\section{Results and Discussion}

Effect of Biological Crust on Soil Physical and Chemical Properties in Latent-Mild Rocky

Desertification Habitat of Salaxi River

\section{Effects of Different Types of BSCs on Physical Properties of Subsoil}

It can be seen from Fig 3 that the soil water holding capacity and soil porosity in the cortex of different types of BSCs in Salaxi research area are moss crust $>$ mixed crust $>$ lichen crust $>$ algae crust $>$ blank, while the soil bulk density shows the opposite rule, blank>algae crust $>$ lichen crust $>$ mixed crust $>$ moss crust. Soil water holding capacity, soil porosity and soil bulk density

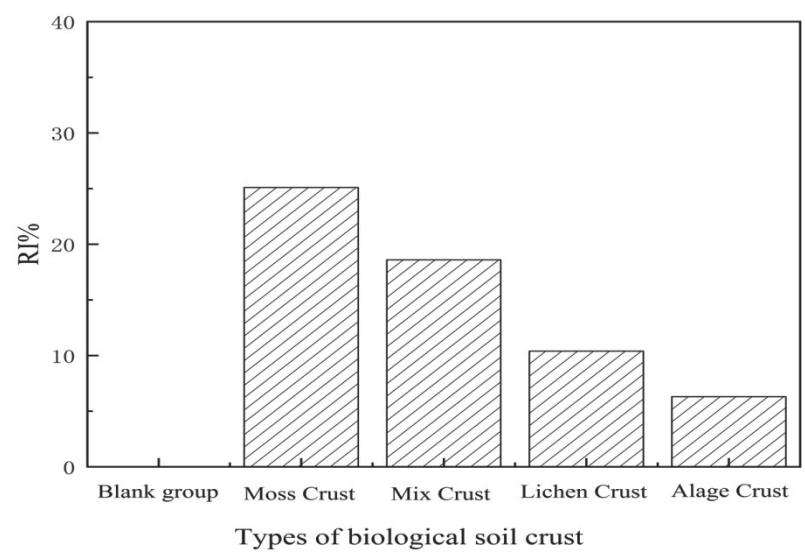

Fig. 1. Effects of biological crust on soil nutrient restoration in Salaxi Research area. 


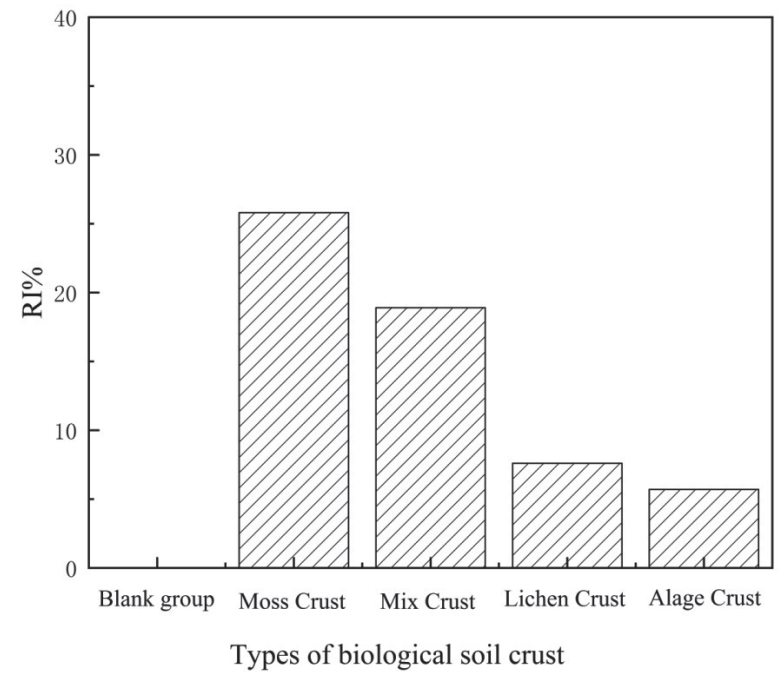

Fig. 2. Effects of biological crust on soil nutrient recovery in Huajiang Research Area.

of different types of BSCs are significantly different $(P<0.05)$.

In the $0-5 \mathrm{~cm}$ and $5-10 \mathrm{~cm}$ soil layers under the crust layer, the changes of soil field water holding capacity and soil porosity are similar to those of the crust, which are moss crust $>$ mixed crust $>$ lichen crust $>$ algal crust $>$ blank (Fig. 3). On the contrary, the soil bulk density is blank $>$ algal crust $>$ lichen crust $>$ mixed crust $>$ moss crust. Except that there was no significant difference in soil porosity between algae crust and lichen crust $(P>0.05)$, there is no significant difference between mixed crust and algae crust and lichen crust in $5 \sim 10 \mathrm{~cm}$ soil layer $(P>0.05)$. There is no significant difference in soil bulk density between bryophyte crust and mixed crust, between lichen crust and algae crust $(P>0.05)$, Among the other types of BSCs, the numerical difference in the $0 \sim 5 \mathrm{~cm}$ and $5 \sim 10 \mathrm{~cm}$ soil layers is significant $(P<0.05)$.

In the vertical soil profile, a comparison of the changes of soil field water capacity, soil porosity and soil bulk density among different soil layers shows that the soil bulk density of BSCs increases with the soil depth, while in other indexes, the same type of BSCs decreases with the depth of neocortical layer. In the soil layers of $0 \sim 5 \mathrm{~cm}$ and $5 \sim 10 \mathrm{~cm}$, there are no significant differences in the porosity of lichen crust soil, the porosity of algal crust soil and the field water capacity of soil $(P>0.05)$, while there are significant differences in the subsoil of other BSCs $(P<0.05)$.

\section{Effects of Different Types of BSCs on the Chemical Properties of the Subsoil}

The contents of total nitrogen, total phosphorus, organic carbon, available nitrogen, available phosphorus and available potassium in the crust show in this manner: moss crust>mixed crust $>$ lichen crust $>$ algae crust $>$ blank (Fig. 3). The contents of total nitrogen, total phosphorus, organic carbon and available nitrogen are significantly different among different types of BSCs $(P<0.05)$; there is no significant difference in the contents of available phosphorus among mixed crusts, lichen crusts and algal crusts $(P>0.05)$, but there is no significant difference in the contents of available potassium between lichen crusts and algal crusts $(P>0.05)$, while the indexes of other types of BSCs are significantly different $(P<0.05)$ and there is no significant difference $(P>0.05)$.

In the $0-5 \mathrm{~cm}$ and $5-10 \mathrm{~cm}$ soil layers under the crust, the total nitrogen, total phosphorus, organic carbon, available nitrogen, available phosphorus and available potassium all show similar rules with the crust, which are moss crust $>$ mixed crust $>$ lichen crust $>$ algae crust $>$ blank (Fig. 3). The results show that there is no significant difference in available potassium content between lichen crust and algal crust $(P>0.05)$, no significant difference in available phosphorus content among mixed crust, lichen crust and algal crust $(P>0.05)$, and there is no significant difference in available nitrogen content between lichen crust and algal crust $(P>0.05)$; other parameters show significant differences among different types of BSCs in $0 \sim 5 \mathrm{~cm}$ and $5 \sim 10 \mathrm{~cm}$ soil layers $(P<0.05)$.

In the vertical section of soil, the analysis of total nitrogen, total phosphorus, organic carbon, available nitrogen, available phosphorus and available potassium among all soil layers leads to two change rules that first the same type of BSCs decreases with the depth of neocorticular layer, and the neocorticular layer is larger than the sublayer soil. There is no significant difference in the content of available $\mathrm{k}$ and organic carbon between lichen crust and algae crust in the subsoil $(P>0.05)$, neither in the content of available $\mathrm{k}$ in the subsoil of mixed crust $(P>0.05)$, while the relevant parameters of other types of BSCs show significant differences among all soil layers. Second the $\mathrm{pH}$ value of the soil increases with the depth of the soil layer, and the mesocortical layer is smaller than that of the substratum. Except for the significant difference of the $\mathrm{pH}$ value between the mosses substratum $(P<0.05)$, the $\mathrm{pH}$ value of the other types of mosses substratum is not significantly different $(P>0.05)$.

\section{Influence of Biological Crust on Physicochemical Properties of Soil under Moderate-Intense Rocky Desertification Habitat Along Huajiang Research Area}

\section{Effects of Different Types of BSCs on Changes in Physical Properties of Subsoil}

Soil water holding capacity and soil porosity of different types of BSCs in Huajiang research area are moss crust $>$ mixed crust $>$ lichen crust $>$ algal crust $>$ blank, but the soil bulk density is in the opposite order: blank $>$ algal crust $>$ lichen crust $>$ mixed crust $>$ moss crust 

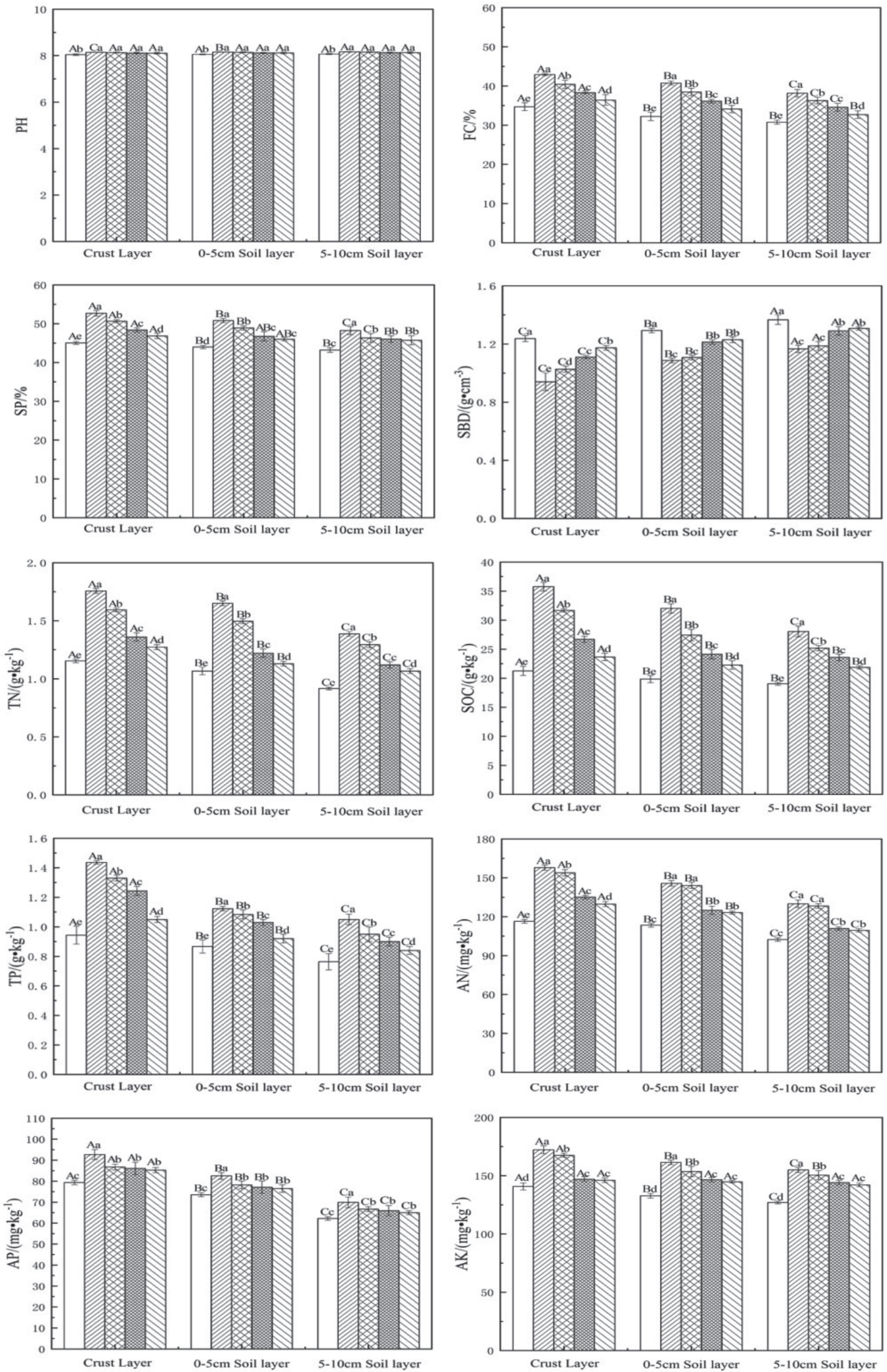

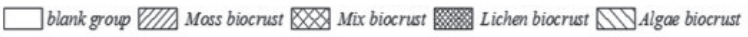

Fig. 3. Physical and chemical properties of different types of crust and its subsoil in Salaxi Research area (different small characters indicate significant differences between the same soil layer and different types of biological crust, $\mathrm{P}<0.05$; Different capital letters indicate that the crust of the same type of organism is significantly different in different soil layers $(P<0.05)$, the same as below. 
(Fig. 4). In different types of BSCs, all other indicators are significantly different $(P<0.05)$ except for the difference of soil porosity and soil bulk density between lichen crust and algae crust $(P>0.05)$ and the difference of soil field water capacity between lichen crust and algae crust $(P>0.05)$.

In the $0-5 \mathrm{~cm}$ and $5-10 \mathrm{~cm}$ soil layers, the variation of soil water holding capacity and soil porosity is similar to that of the crust, which manifests as moss crust $>$ mixed crust $>$ lichen crust $>$ algae crust $>$ blank, and only the soil bulk density in the subsoil of crust is blank $>$ algal crust $>$ lichen crust $>$ mixed crust $>$ moss crust (Fig. 4). In the subsoil, the difference is significant $(P<0.05)$ in all the rest types of BSCs of $0 \sim 5 \mathrm{~cm}$ and $5 \sim 10 \mathrm{~cm}$ soil layers except the difference in soil water holding capacity between moss crust and mixed crust, lichen crust and algal crust $(P>0.05)$, the difference in soil porosity between lichen crust and algal crust $(P>0.05)$, and difference in soil bulk density among mixed crust, lichen crust and algal crust $(P>0.05)$. .

In the vertical section of soil, a comparison of the numerical differences of soil field water capacity, soil porosity and soil bulk density among different soil layers shows that the soil bulk density content increases with the soil depth, while other indexes of the same type of BSCs decreases with the depth of the neocortical layer. The bulk density of BSCs of different types is significantly different among different layers $(P<0.05)$, and the soil porosity of the four types of crust is not significantly different in the neocortical layer and the $0-5 \mathrm{~cm}$ soil layer $(P>0.05)$, but is significantly different from that of the $5-10 \mathrm{~cm}$ soil layer $(P<0.05)$. The field water capacity of lichen crust and algae crust is not significantly different between the two layers of the crust and the lower layer $(P>0.05)$, and the indexes of other types of BSCs are significantly different between each layer $(P<0.05)$.

\section{Effects of Different Types of BSCs on the Chemical Properties of the Subsoil}

The contents of total nitrogen, total phosphorus, organic carbon, available nitrogen, available phosphorus, and available potassium in the cortex all manifest as the blank $<$ algae crust $<$ lichen crust $<$ mixed crust $<$ moss crust (Fig. 4). Among them, total nitrogen, organic carbon and available nitrogen are significantly different among different BSCs $(P<0.05)$. All other BSCs show significant differences in total phosphorus, available potassium and available phosphorus $(P<0.05)$ except for lichen crust and algae crust, total phosphorus, available potassium and available phosphorus contents $(P>0.05)$. There is no significant difference in $\mathrm{pH}$ value between different BSCs $(P>0.05)$.

In the layers $0 \sim 5 \mathrm{~cm}$ and $5 \sim 10 \mathrm{~cm}$ beneath the crust, total nitrogen, total phosphorus, organic carbon, available nitrogen, available phosphorus, and available potassium all show similar laws to the crust, which is blank $<$ algae crust $<$ lichen crust $<$ mixed crust $<$ moss crust (Fig.4). Except for lichen crust and algae crust, the contents of total phosphorus, available nitrogen, available phosphorus and available potassium are not significantly different $(P>0.05)$, all other parameters are significantly different between different types of BSCs in soil layers of $0 \sim 5 \mathrm{~cm}$ and $5 \sim 10 \mathrm{~cm}(P<0.05)$.

In the vertical section of the soil, a comparison of the numerical differences of total nitrogen, total phosphorus, organic carbon, available nitrogen, available phosphorus and available potassium between the basal layer and the sublayer soil shows that the same type of BSCs decreases with the depth of basal layer, and the basal layer is larger than the sublayer soil. All parameters of other types of BSCs among different soil layers $(P<0.05)$ show significant differences but there is no significant difference in organic carbon content between lichen crust and $0-5 \mathrm{~cm}$ soil layer $(P>0.05)$, neither is in available phosphorus content between $0-5 \mathrm{~cm}$ soil layer and 5-10 cm soil layer $(P>0.05)$; meanwhile, the content of available potassium in lichen crust and algal crust does not change significantly $(P>0.05)$. The $\mathrm{pH}$ value of soil increases with the increase of soil depth, and the soil crust is smaller than the subsoil. The difference of $\mathrm{pH}$ value between different types of crust subsoil is not significant $(P>0.05)$ except for $\mathrm{pH}$ value between the subsoil of moss crust $(P<0.05)$.

\section{Correlation Analysis of Physical and Chemical Properties of Biological Crust Soil \\ Correlation Analysis of Physical and Chemical Properties of Biological Crust Soil in Salaxi Research Area}

As it can be clearly seen from Table 2, soil $\mathrm{pH}$ value under biological crust cover in Salaxi Research area is not correlated with total nitrogen, available nitrogen, total phosphorus, available phosphorus, available potassium, soil organic carbon, soil bulk density, soil field water capacity and soil porosity while the soil bulk density is negatively correlated with total nitrogen, available nitrogen, total phosphorus, available phosphorus, available potassium, soil organic carbon, soil field water capacity and soil porosity. Except for $\mathrm{pH}$ value and soil bulk density, the other indexes all show significant positive correlation.

\section{Correlation Analysis of Physical and Chemical Properties of Biological Crust Soil in Huajiang Research Area}

It can be clearly seen from Table 3 that soil $\mathrm{pH}$ value under biological skin cover in Huajiang research area is not correlated with total nitrogen, available nitrogen, total phosphorus, available phosphorus, available potassium, soil organic carbon, soil bulk density, soil field water capacity and soil porosity but soil bulk density is negatively correlated with 

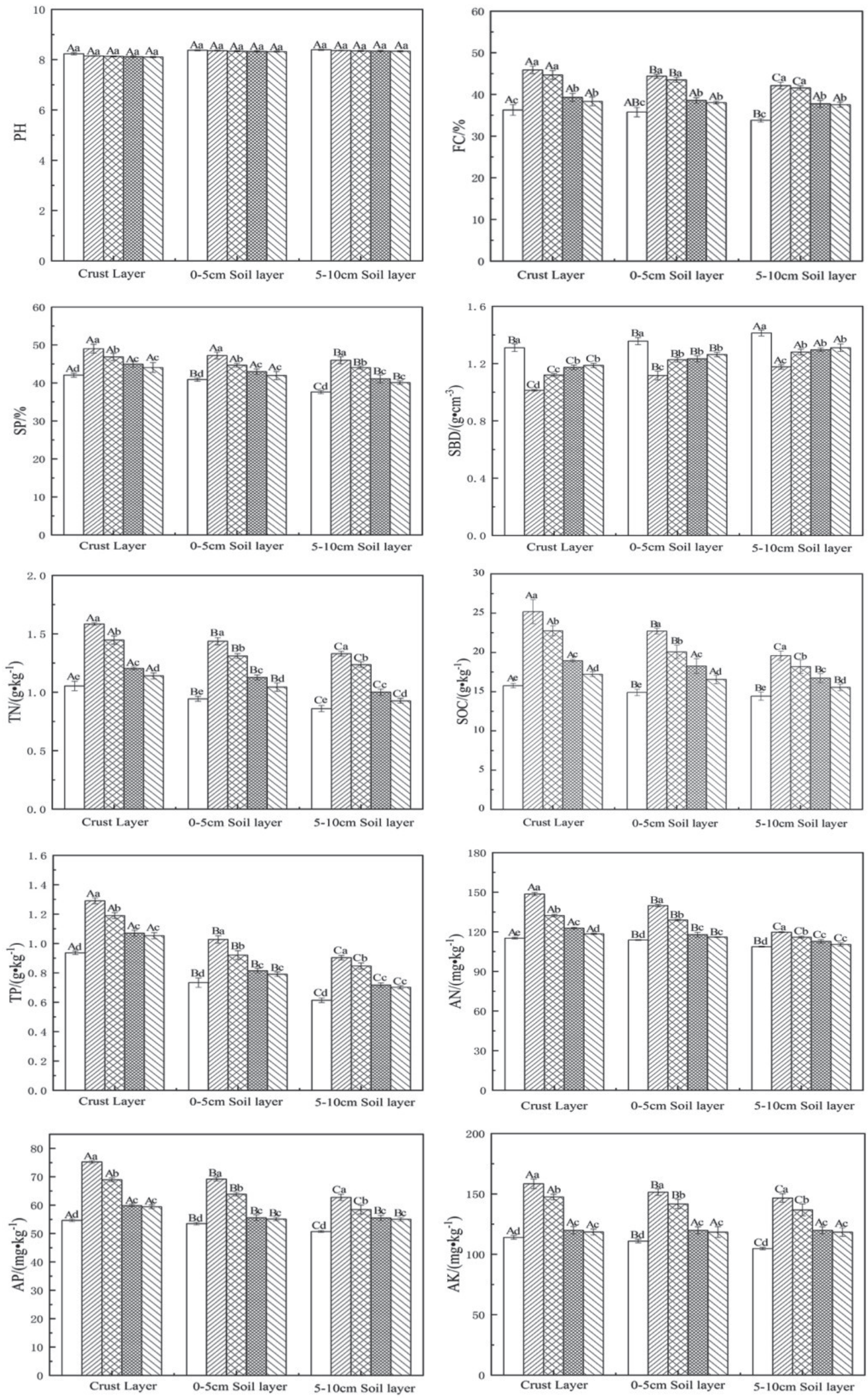

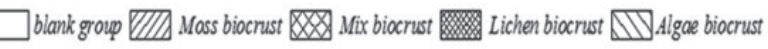

Fig. 4. Physical and chemical properties of different types of crust and subsoil in Huajiang research area. 
Table 2. Correlation coefficient of physical and chemical properties of biological crust soil in Salaxi research area.

\begin{tabular}{|c|c|c|c|c|c|c|c|c|c|c|}
\hline Factor & $\mathrm{pH}$ & $\mathrm{TN}$ & $\mathrm{AN}$ & $\mathrm{TP}$ & $\mathrm{AP}$ & $\mathrm{AK}$ & $\mathrm{SOC}$ & $\mathrm{SBD}$ & $\mathrm{FC}$ & $\mathrm{SP}$ \\
\hline $\mathrm{pH}$ & & 0.875 & 0.903 & 0.882 & 0.916 & 0.951 & 0.887 & -0.907 & 0.902 & 0.932 \\
\hline $\mathrm{TN}$ & & & $0.985^{* *}$ & $0.992^{* *}$ & $0.922^{*}$ & $0.977^{* *}$ & $0.993^{* *}$ & $-0.996^{* *}$ & $0.989^{* *}$ & $0.983^{* *}$ \\
\hline $\mathrm{AN}$ & & & & $0.976^{* *}$ & $0.882^{*}$ & $0.983^{* *}$ & $0.967 * *$ & $-0.994^{* *}$ & $0.969^{* *}$ & $0.965^{* *}$ \\
\hline $\mathrm{TP}$ & & & & & $0.919 *$ & $0.966^{* *}$ & $0.993^{* *}$ & $-0.992^{* *}$ & $0.997 * *$ & $0.983^{* *}$ \\
\hline $\mathrm{AP}$ & & & & & & $0.944^{*}$ & $0.952^{*}$ & $-0.920 *$ & $0.945^{*}$ & $0.971^{* *}$ \\
\hline $\mathrm{AK}$ & & & & & & & $0.973^{* *}$ & $-0.987 * *$ & $0.973^{* *}$ & $0.987^{* *}$ \\
\hline $\mathrm{SOC}$ & & & & & & & & $-0.989 * *$ & $0.997 * *$ & $0.993^{* *}$ \\
\hline $\mathrm{SBD}$ & & & & & & & & & $-0.990^{* *}$ & $-0.986^{* *}$ \\
\hline $\mathrm{FC}$ & & & & & & & & & & $0.993^{* *}$ \\
\hline $\mathrm{SP}$ & & & & & & & & & & \\
\hline
\end{tabular}

Note: * indicates the correlations were significant $(\mathrm{P}<0.05), * *$ indicates the correlations were extremely significant $(\mathrm{P}<0.01)$.

(TN: Soil total nitrogen; AN: Soil available nitrogen; TP: Soil total phosphorus; AP: Soil available phosphorus; AK: Soil Available k; SOC: Soil organic carbon; SBD: Soil bulk density; FC: Soil field capacity; SP: Soil porosity)

Table 3. Correlation coefficient of physical and chemical properties of biological crust soil in Huajiang research area.

\begin{tabular}{|c|c|c|c|c|c|c|c|c|c|c|}
\hline Factor & $\mathrm{pH}$ & $\mathrm{TN}$ & $\mathrm{AN}$ & $\mathrm{TP}$ & $\mathrm{AP}$ & $\mathrm{AK}$ & $\mathrm{SOC}$ & $\mathrm{SBD}$ & $\mathrm{FC}$ & $\mathrm{SP}$ \\
\hline $\mathrm{pH}$ & & 0.819 & 0.921 & 0.877 & 0.852 & 0.907 & 0.975 & -0.901 & 0.943 & 0.879 \\
\hline $\mathrm{TN}$ & & & $0.976^{* *}$ & $0.990^{* *}$ & $0.991^{* *}$ & $0.992^{* *}$ & $0.995^{* *}$ & $-0.951^{*}$ & $0.987^{* *}$ & $0.978^{* *}$ \\
\hline $\mathrm{AN}$ & & & & $0.974 * *$ & $0.990^{* *}$ & $0.980^{* *}$ & $0.972^{* *}$ & $-0.924^{*}$ & $0.939^{*}$ & $0.959^{* *}$ \\
\hline $\mathrm{TP}$ & & & & & $0.995^{* *}$ & $0.986^{* *}$ & $0.991^{* *}$ & $-0.982^{* *}$ & $0.982^{* *}$ & $0.997^{* *}$ \\
\hline $\mathrm{AP}$ & & & & & & $0.995^{* *}$ & $0.985^{* *}$ & $-0.959^{*}$ & $0.975^{* *}$ & $0.986^{* *}$ \\
\hline $\mathrm{AK}$ & & & & & & & $0.978^{* *}$ & $-0.937^{*}$ & $0.985^{* *}$ & $0.974^{* *}$ \\
\hline $\mathrm{SOC}$ & & & & & & & & $-0.967 * *$ & $0.976^{* *}$ & $0.983^{* *}$ \\
\hline $\mathrm{SBD}$ & & & & & & & & & $-0.952^{*}$ & $-0.992^{* *}$ \\
\hline $\mathrm{FC}$ & & & & & & & & & & $0.976^{* *}$ \\
\hline $\mathrm{SP}$ & & & & & & & & & & \\
\hline
\end{tabular}

Note: * indicates the correlations were significant $(\mathrm{P}<0.05)$, ** indicates the correlations were extremely significant $(\mathrm{P}<0.01)$.

(TN: Soil total nitrogen; AN: Soil available nitrogen; TP: Soil total phosphorus; AP: Soil available phosphorus; AK: Soil Available k; SOC: Soil organic carbon; SBD: Soil bulk density; FC: Soil field capacity; SP: Soil porosity)

total nitrogen, available nitrogen, total phosphorus, available phosphorus, available potassium, soil organic carbon, soil field water capacity and soil porosity. Except for $\mathrm{pH}$ value and soil bulk density, the other indexes all showed significant positive correlation.

\section{Effects of Different Types of Biological Crust on Soil Nutrient Recovery}

Soil nutrient recovery index (RI) can indicate the degree of soil recovery. This study calculates the soil recovery index under different types of BSCs by means of the soil recovery index formula with the blank group as the control group. According to (Fig. 1) of the Salaxi research area: a comparison of the blank groups shows that the soil nutrient recovery indexes of moss crust, mixed crust, lichen crust and algae crust are $25.1 \%, 18.6 \%, 10.4 \%$ and $6.3 \%$, respectively. And from (Fig. 2) of the Huajiang research area, a comparison of the blank groups shows that the soil nutrient recovery indexes of moss crust, mixed crust, lichen crust and algae crust are $25.8 \%, 18.9 \%, 7.6 \%$ and $5.7 \%$, respectively. Studies show that in regions with different levels of rocky desertification, biological crust has a certain recovery function for soil nutrients, and BSCs at different stages of succession have different degrees of recovery for soil nutrients, which are specifically manifested as moss crust and mixed crust $>$ lichen crust and algae crust. 


\section{Effect of Biological Crust on Soil Physical and Chemical Properties in Karst Rocky Desertification Area}

BSCs are important surface cover types in karst rocky desertification areas, which can maintain the dynamic balance of soil ecosystem with their special physiological structure and strong adaptive mechanism [16]. They play an important role in karst ecosystem as they have positive effects on improving soil environment, stabilizing hydrological environment, and developing and succeeding process of animals and plants (Fig. 5). Previous studies have shown that there are differences in the ecological functions and ecological benefits of different types of BSCs because of the differentiated morphological functions and varied components [17]. In this study, the total nitrogen, available nitrogen, total phosphorus, available phosphorus, available potassium, soil organic carbon, soil bulk density, soil field water holding capacity and soil porosity under the coverage of BSCs manifest as moss crust $>$ mixed crust $>$ lichen crust $>$ algae crust $(P<0.05)$ (Fig. 3, Fig. 4). On the one hand, there are differences in biomass among different types of BSCs, which are generally reflected as moss crust $>$ lichen crust $>$ algae crust. In the process of succession development, the exudates of BSCs, litter and biological residues on the surface layer are decomposed by microorganisms to form humic soil layer, promoting as a result the accumulation of nutrients such as carbon, nitrogen, phosphorus and potassium in the soil, which is also the main reason for affecting the physical and chemical properties of the underlying soil of BSCs [18]. In addition, when the crust vegetation starts from the propagation of algae and fungi, the surface coverage and roughness would gradually increase with the improvement of the shallow soil environment to capture more atmospheric dust, increase the thickness of crust vegetation, the content of fine particles and nutrients in soil, and develop lichen crust and moss crust begin, so consequently, there is a obvious promotion to the water retention, soil consolidation, and nutrition in the crust. In this process, when the species of constituent plants from low to high, and the population richness and community diversity from small to large, the evolution of BSCs will be completed with the advance of time and the improvement of micro environment conditions. Generally speaking, bryophyte crust, as the vegetation type at the end of succession (Fig. 6), has the highest

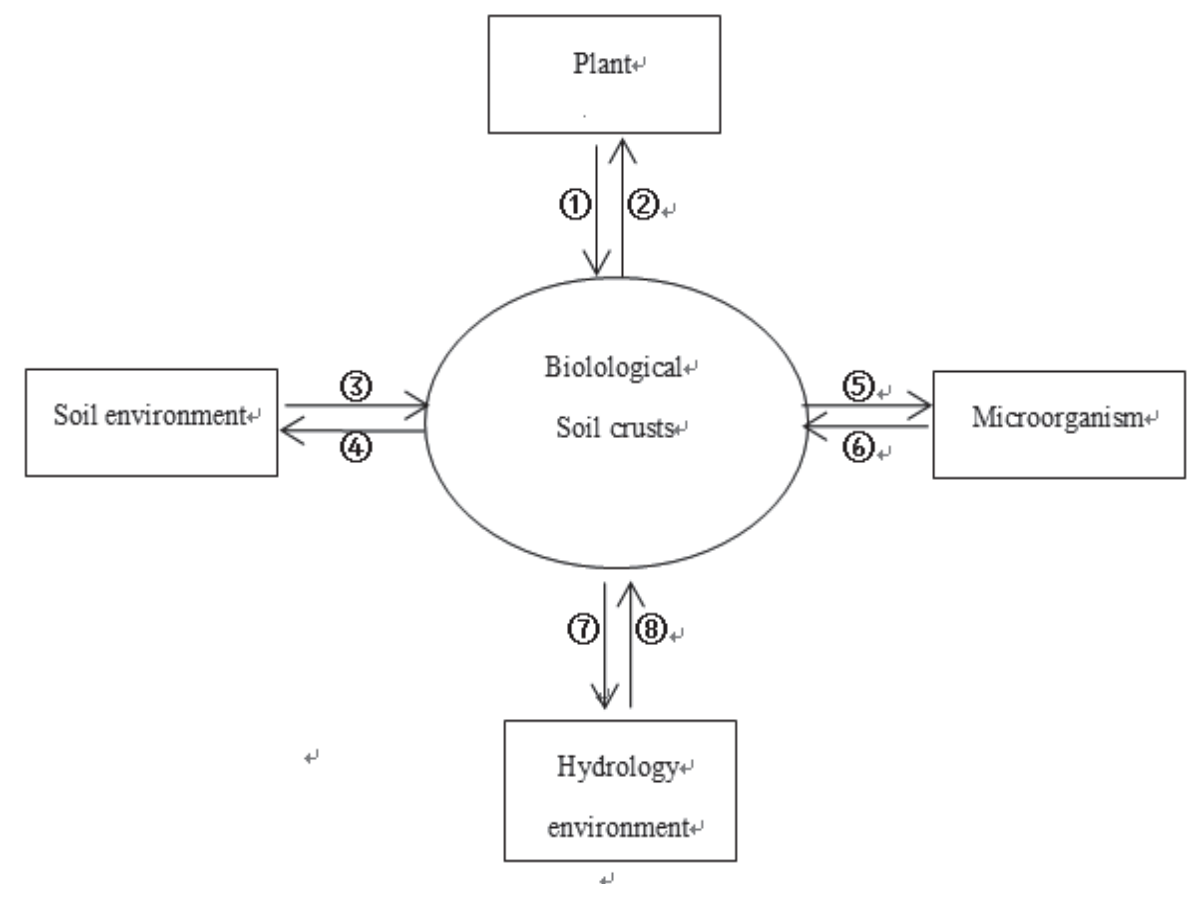

Fig. 5. Response mechanism of biological soil crust and Karst ecosystem.

Note: 1. Trace elements and nutrients were provided for biological soil crusts, succession process of crust vegetation was promoted, and the suitable growth environment was controlled. 2. Releasing the remaining nutrients and water to ensure the growth and development of plants and capture seeds, regulating soil temperature and humidity, and improving the soil physical properties. 3 . The space carrier of biological soil crusts, providing them with various material energy required for survival. 4 . The organic matter and the trace elements were accumulated, the spatial exchange of water and heat was controlled, the physical and chemical properties of soil were improved, the soil layer thickness and stability of soil were increased, the soil environment was improved. 5. Providing them with living space and corresponding nutrient sources, and regulating growth and development environmental indicators such as soil temperature and humidity. 6. An participant in the succession process of biological soil crusts, an important part of biological processes in the microenvironment. 7. Controlling the process of surface infiltration and runoff formation and changing the pattern of soil water redistribution, enhancing water retention of soil and status of condensed water capture. 8. Providing moisture, humidity and a suitable environment for biological soil crusts, affecting its occurrence and progress. 


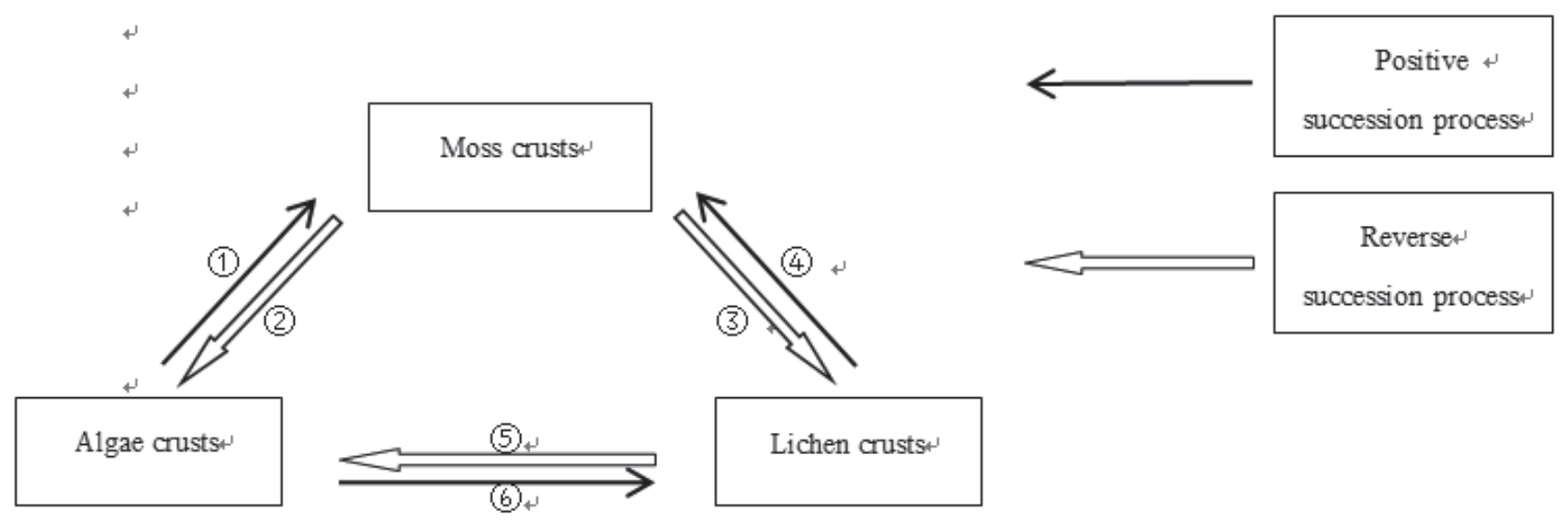

Fig. 6. A schematic flowchart showing the succession of biological soil crusts.

Note: 1. Artificial cultivation technology, stable soil matrix and rich soil organic matter, sufficient hydrothermal conditions, good terrain conditions, rich biodiversity, little external force, and relatively stable ecosystem. 2. The composition structure of soil, species, etc. has been damaged by external forces, the regional ecological environment has continued to decline, soil and water loss has been serious, the land degradation has increased, and mountain disasters have occurred frequently. 3. Ecosystem stability is aborted, the soil physical properties are poor, biodiversity is reduced, and human activities are seriously disrupted. 4. Artificial cultivation technology, the ecological environment such as hydrology, biology, climate and terrain is in good condition, the population has strong anti-interference ability, and the ecosystem is relatively stable. 5. Long-term excessive intensive planting, animal husbandry, and severe human activity, disrupted ecosystem stability, and spreading ecological disasters such as desertification and rocky desertification, and the degenerate ecological environment. 6.Artificial breeding, good habitat conditions, sufficient species diversity, stable soil matrix, and less external disturbance. (All of the above are normal or interferential factors in the succession stage).

ecological function among all types of BSCs. On the other hand, as the succession of BSCs effectively improves environmental factors such as hydrothermal conditions, the increase of biomass, the improvement of habitat conditions, and the enhancement of microbial biodiversity in the crust and soil layer would further strengthen the microbial decomposition to ensure the effective accumulation of carbon, nitrogen, phosphorus, potassium and other nutrients in the soil [19].

BSCs being the important sources of carbon and nitrogen in karst rocky desertification area, its chlorophyll content increases with its succession development. The fixation capacity of carbon and nitrogen is gradually enhanced through physiological regulation functions such as photosynthesis, respiration and metabolism. Previous researches discover that the annual carbon sequestration of algae crust is $2.9 \mathrm{~g} \cdot \mathrm{m}^{-2} \cdot \mathrm{a}^{-1} \sim 11.2 \mathrm{~g} \cdot \mathrm{m}^{-2} \cdot \mathrm{a}^{-1}$, lichen crust is $3.5 \mathrm{~g} \cdot \mathrm{m}^{-2} \cdot \mathrm{a}^{-1} \sim 37.2 \mathrm{~g} \cdot \mathrm{m}^{-2} \cdot \mathrm{a}^{-1}$, and moss crust is $26.8 \mathrm{~g} \cdot \mathrm{m}^{-2} \cdot \mathrm{a}^{-1} \sim 64.9 \mathrm{~g} \cdot \mathrm{m}^{-2} \cdot \mathrm{a}^{-1}[20]$. At the same time, the soil nitrogen conversion rate and its sensitivity to temperature under BSCs mulching are higher than those in non crusted soil, so the nitrogen supply in soil is enhanced to improve the efficiency of nitrogen transformation and cycling, which plays an essential role in the balance and stability of soil system. Relevant studies by Cong Chunlei in Guizhou karst areas confirm that the nitrogen fixation activity there is between 2.5 mol $61.5 \mathrm{~mol}$, among which the average of algal crust $(14.5 \mathrm{~mol})<$ lichen crust $(19.7 \mathrm{~mol})<\operatorname{moss}$ crust $(28.2 \mathrm{~mol})$, and when the average annual nitrogen fixation amount of BSCs is between $13.3 \mathrm{mg} \cdot \mathrm{m}^{-2} \cdot \mathrm{a}^{-1} \sim 38.13 \mathrm{mg} \cdot \mathrm{m}^{-2} \cdot \mathrm{a}^{-1}$, the rule is algal crust $<$ lichen crust $<$ moss crust.[21] Studies of the physical and chemical properties of BSCs in Molopo basin, South Africa by Thomas et al. show that BSCs could promote the stable growth of carbon and nitrogen in soil through the ability to fix and maintain carbon and nitrogen [22]. Both studies by $\mathrm{Hu}$ et al in Tengger Desert and by $\mathrm{Li}$ Xinrong in Horqin Desert also confirm that BSCs can significantly improve soil carbon, nitrogen, phosphorus, potassium and other nutrients [23-24], which is consistent with the research results of this paper. This reveals the fact that BSCs input carbon, nitrogen and other elements in the ecosystem and transform them into soil nutrients for plant growth, which proved the key role of BSCs in the carbon, nitrogen, phosphorus and potassium cycle and the outstanding contribution to soil nutrient accumulation under karst habitats. In addition, the soil bulk density in this study is manifested as algal crust $>$ lichen crust $>$ and mixed crust $>$ moss crust, which is the same as the results obtained by Huang Qiaoyun et al in the loess desert area [25].

In the results of this experiment, except for $\mathrm{pH}$ value, the correlation of other physical and chemical properties between crust and subsoil is significant (Table 2, Table 3), indicating that the change law of physicochemical properties of crust and subsoil is synchronous. A comparison of the values of soil vertical profile shows that the nutrient content in the crust and $0-5 \mathrm{~cm}$ soil layer of BSCs is significantly higher than that of $5-10 \mathrm{~cm}$ soil layer, decreasing with the depth of the crust layer, which is consistent with the conclusions obtained by Emma $\mathrm{K}$ et al. in southern Australia, Researchers in Gurbantunggut Desert area in Xinjiang, and in Loess Plateau of China [26-28]. 
indicating that BSCs can affect the soil physical and chemical properties of the underlying surface, and the impact on the subsoil decreases with the depth of the soil. In addition, different types of BSCs have different structure, composition and ecological function due to different succession periods, resulting in discrepancy in soil nutrients covered by different BSCs, which is manifested in this study as algae crusts $<$ lichen crusts $<$ mixed crusts $<$ moss crusts, consistent with the results by researchers in Gurbantunggut Desert, Xinjiang, China, and that by Researchers in arid areas of Iran [29-31]. In addition, nutrients in the crust covered by BSCs eluviates during rainfall infiltration to affect the nutrient content in the middle and lower layers of soil. The conclusion of this study is contrary to that by Dujun et al. in Tengger Desert [32], but it is consistent with the conclusion by Wang et al in Guizhou karst area and by others in Northwest China which could be attributed to the fact that in arid semi-arid desert area, limited by the rainfall infiltration depth, the infiltration nutrients generally stay in the soil surface layer above $5 \mathrm{~cm}$. However, the rich rainfall in the drainage basin in this research area would result in eluviation of the soil surface nutrients with the precipitation infiltration, affecting the nutrient content of the middle and lower layers of soil. On the other hand, as soil in desert area features with sandy soil, but in this research area yellow soil and purple sand soil are the main contents, it is of course richer in carbon, nitrogen, phosphorus and other nutrients. The environmental conditions in the research area is better when comprehensively compared with the climate, hydrology, vegetation type and coverage, geology and geomorphology and many other factors; therefore, the soil carbon, nitrogen, phosphorus, potassium and other nutrient contents in this area are higher than those in arid and semiarid desert areas. In addition, there is no significant difference in soil $\mathrm{pH}$ value among different types of BSCs, but it increases with the increase of soil depth, which is consistent with the research results by Miralles et al in Tavernas desert in Spain and those by Song et al in Tengger Desert in China [33-34]. The reason may be that in the process of succession and development of BSCs, cryptophytes in BSCs propagate in large quantities, which with the enhancement of physiological functions such as photosynthesis and respiration, would generate continuous accumulation of the organic acids secreted by plants and the microbial decomposition products in the root system, and neutralization of the $\mathrm{pH}$ value by rainfall infiltration. The changes of soil $\mathrm{pH}$ value in this area are not obvious due to many factors.

The Significance of Biological Crust in Improving Soil Environment in Karst Area and Comprehensive Control of Rocky Desertification

The karst landform in South China is characterized by complex habitat conditions, large rainfall, high bedrock exposure, slow soil formation rate of parent rock, serious surface erosion and frequent natural disasters, which easily leads to rocky desertification. BSCs can effectively improve the soil environment through its unique function, which is of great significance for the formation and development of soil in karst soil system, the effective accumulation and circulation of soil nutrients and the maintenance of soil environmental stability [35]. The results of this study verified the outstanding contribution of BSCs to the cycling of carbon, nitrogen, phosphorus and potassium in soil environment and the storage and accumulation of soil nutrients in different karst rocky desertification habitats (Fig. 1, Fig. 2, Fig. 3, Fig. 4).

In addition, walnut and Zanthoxylum bungeanum are special cash trees for controlling rocky desertification in karst areas, which have been popularized and applied in Salaxi and Huajiang research areas, and have brought benefits to local ecology and economy. However, due to the long growth cycle, sparse branches and leaves of walnut and Zanthoxylum bungeanum trees, the interception effect of rainfall infiltration and runoff erosion is limited. [36] At the same time, owing to their strong nutrient plunder in the soil to make it difficult for the shrubs and grasses under the trees to survive, it is very easy to cause large area of surface exposure, everserious soil erosion and underground leakage, which further induces the formation of rocky desertification [37]. With its high compatibility with different types of habitats and strong stress resistance, BSCs can directly absorb water and nutrients from the body surface through special physiological structure and root system to promote the accumulation of nutrient content in soil, and effectively improve soil physical and chemical properties, so as to maintain the dynamic balance of karst soil system [38]. Therefore, cultivating BSCs under walnut and Zanthoxylum bungeanum forests can effectively reduce the erosion of soil surface by exogenous forces, and obtain greater ecological benefits. The popular rocky desertification control mainly adopts the "forest-shrub-grass" vegetation combination mode, the three-dimensional development mode of mixed agriculture and forestry combined with water and soil leakage control technology, but due to the large area of rock exposed on the surface, obvious the terrain segmentation, and poor vegetation site conditions, the conventional control with large area of grass and woody plants demands a long period and generates no ecological benefits. Compared with the traditional rocky desertification control methods, the artificial cultivation of BSCs has the advantages of low cost in the early stage, easy cultivation in the middle stage, convenient maintenance in the later stage, short growth cycle and high survival rate, good stress tolerance, high ecological value and high compatibility with different habitats. So its strong ecological restoration would make it the pioneer plants of environmental governance, which a new complement to existing karst rocky desertification control measures [39]. 


\section{Conclusion}

The Salaxi Karst Plateau Mountain latent-mild rocky desertification research area and Huajiang Karst Plateau Canyon moderate-intense rocky desertification research area, representing four different levels(latentmild-moderate-intense) of rocky desertification regions, are the most typical and comprehensive, the most complex ecological fragile areas with the longest evolution time in China. Though different types of BSCs have different effects on soil physical and chemical properties in different karst rocky desertification areas, they all have positive effects on soil nutrient accumulation on the underlying surface to significantly improve the soil environment in karst ecological fragile areas. Comparisons of the soil dates of different types of BSCs show a succession of moss crusts $>$ mixed crusts $>$ lichen crusts $>$ algal crusts, at the end of which the moss crusts generates the highest ecological benefits. In the vertical profile, the contents of carbon, nitrogen, phosphorus, potassium and other nutrients in the subsoil of all types of BSCs decrease with the deepening of soil depth, indicating that BSCs have the most significant effect on the surface soil.

In addition to $\mathrm{pH}$ value, there were significant correlations between the physical and chemical properties (total nitrogen, available nitrogen, available potassium, total phosphorus, available phosphorus, soil organic carbon, soil bulk density, soil field capacity, soil porosity and available potassium) between different types of BSCs. In the meantime, comparisons of the effects of BSCs on soil nutrient content in different types of research areas reveal that the influence of BSCs on soil physical and chemical properties is similar in rules but different with degrees in different habitats, which could be attributed to the ecological factors in different regions like the soil types, the soil temperature and humidity, the climatic conditions, the animal and plant community composition, the topography and landform and soon.

\section{Acknowledgements}

This work was supported by the Key Project of Science and Technology Program of Guizhou Province: Poverty Alleviation Model and Technology demonstration for Ecoindustries Derivated from the karst desertification control (No. 54112017 Qiankehe Pingtai Rencai), the Project of National Key Research and Development Program of China in the $13^{\text {th }}$ Five-year Plan Period: Ecological Industry Model and Integrated Technology Demonstration of the Karst Plateau-Gorge Rocky Desertification Control (2016YFC0502607); the World Top Discipline Program of Guizhou Province: Karst Ecoenvironment Sciences(No.125,2019 Qianjiao Keyan Fa).

\section{Conflict of Interest}

The authors declare no conflict of interest.

\section{References}

1. HAN B.H., NIU D.C., HE L., REN Y.T., WU R., FU H. A review on the development and effect of biological soil crusts. Pratacultural Science. 34 (9), 1793, 2017.

2. ZHENG Z.H., XIONG K.N., RONG L., CHI Y.K. Application potential of biological soil crusts in karst ecological management. Acta Botanica BorealiOccidentalia Sinica. 40 (6), 1075, 2020.

3. JI X.H., ZHANG Y.M., ZHOU X.B., WU L., ZHANG J. Spatial distribution of soil properties covered by moss crusts on different scales. Acta Ecologica Sinica, 34 (14), 4006, 2014

4. SHEN J.C., ZHANG Z.H., WANG H.H., HUANG H., WANG Z.H. Water Retention Capacity of Autumn Mosses in South Stone Forest of Guiyang Karst Park. Journal of Ecology and Rural Environment. 33 (10), 907, 2017.

5. LI J.F., JIA S.H., WANG Z.H., ZHANG Z.H. The diversity of bryophytes and their distribution associated with environmental factors during the process of karst rocky desertification. Ecological Science. 34 (1), 68, 2015.

6. ZHANG Y., XIONG K.N.,YU Y.H., QIN Y., LI T.L. Stoichiometric characteristics of ecological-economic forests in karst rocky desertification areas of southern China. Austrian Journal of Forest Science. 137 (2), 109, 2020.

7. XIONG K.N., LI J., LONG M.Z,. Features of Soil and Water Loss and Key Issues in Demonstration Areas for Combating Karst Rocky Desertification. Acta Geographica Sinica. 67 (7), 878, 2012.

8. CHENG C, LI X.N., LI Y.J., LONG M.Z. Application potential of bryophyte soil crust on the control of karst rocky desertification. Chinese Journal of Applied Ecology. 30 (7), 2501, 2019.

9. MIRALLE S.I., SORIA. R., LUCAS-BORJ A.M.E., SORIANO M., ORTEGA R. Effect of biocrusts on bacterial community composition at different soil depths in Mediterranean semi -arid ecosystems. Science of the total environment. 733 (10), 1016, 2020.

10. LI L., XIONG K.N. Study on peak cluster-depression rocky desertification landscape evolution and human activity-influence in South of China. European journal of remote sensing. 47 (2), 120, 2020.

11. ZHANG Y., XIONG K.N.,Yu Y.H., YANG S.,LIU H.Y. Stoichiometric characteristics and driving mechanisms of plants in karst areas of rocky desertification of southern china. Applied ecology and environmental research, 18 (1), 1961, 2020.

12. DAI Q.H., PENG X.D., WANG P.J., SHAO H.B. Surface erosion and underground leakage of yellow soil on slopes in karst regions of southwest China. Land Degradation and Development. 29 (8), 2438, 2018.

13. LIU R., SHENG J.C., ZHANG Z.H. Study on the Significance of Ecological Restoration of Four Bryophytes in Karst Rocky Desertification Area. Journal of Soil and Water Conservation., 32 (6), 220, 2018.

14. CHU B.B., WANG J.Y., ZHAN X.C., YAO W.S. TXRF Study on Mobile Forms of Elements in Soils. Spectroscopy and Spectral Analysis. 40 (7), 2278, 2020. 
15. SLATE. MANDY L., DURHAM. REBECCA A., PEARSON, DEAN E. Strategies for restoring the structure and function of lichen-moss biocrust communities. Restoration ecology. 28 (2), 160, 2020.

16. TUCKER C., ANTONINKA A., DAY N., POFF B., REED S. Biological soil crust salvage for dryland restoration: an opportunity for natural resource restoration. Restoration ecology. 28 (2), 9, 2020.

17. SONG G., LI X.R., HUI R. Biological soil crusts increase stability and invasion resistance of desert revegetation communities in northern China. Ecosphere. 11 (2), 10, 2020.

18. LI X.Q., ZHANG Y.M. The horizontal distribution of soil physicochemical properties, soil enzyme activities, and microbial biomass in moss crust patch in a temperate desert. Chinese Journa of Ecology. 37 (7), 2114, 2018.

19. CHIQUOINE L.P., ABELLA S.R., GREENWOOD.J.L., DECORTE A. Unexpected side effects in biocrust after treating non-native plants using carbon addition. Restoration ecology. 28 (2), 32, 2020.

20. ZHANG J., XU M., ZOU X., XU M.X. Effects of Biological Crusts on Soil Properties Under Different Soil and Vegetation Habitats. Journal of Soil and Water Conservation. 33 (5), 323, 2019.

21. CONG C.L., LIU T.L., KONG X.Y., ZHANG X.Q. Flora and species diversity of epilithic mosses on rock desertification in the Puding karst area. Carsologica Sinica. 36 (2), 179, 2017.

22. THOMAS A.D., DOUGILL A.J. Distribution and characteristics of cyanobacterial soil crusts in the Molopo Basin, South Africa. Journal of Arid Environments. 64 (2), 270, 2006.

23. HU R., WANG X.P., PAN Y.X., ZHANG Y.F., ZHAO H. Seasonal variation of net $\mathrm{N}$ mineralization under different biological soil crusts in Tengger Desert, North China. Catena: An Interdisciplinary Journal of Soil Science Hydrology-Geomorphology Focusing on Geoecology and Landscape Evolution . 127 (9), 15, 2015

24. LI X.R., TAN H.J., HUI R., ZHAO Y., HUANG L.,JIA R.L., SONG G. Researches in biological soil crust of China:A review. Chinese Science Bulletin, 63 (23), 2320, 2018.

25. YANG Q.Y., ZHAO Y.G., BAO T.L., DING Q., LIU G.L. Soil ecological stoichiometry characteristics under different types of biological soil crusts in the hilly Loess Plateau region. Chinese Journal of Applied Ecology. 30 (8), 2699, 2019

26. KE T., ZHANG Y.R., YE C.R., ZHOU X.J., CHEN L.Z., AN X.L., DE PHILIPPIS R. The facilitative effects of shrub on induced biological soil crust development and soil properties. Applied Soil Ecology. 137 (16), 129, 2019.

27. EMMA K. STEGGLES., JOSE M. FACELLI., PHILLIP J. AINSLEY. Biological soil crust and vascular plant interactions in Western Myall (Acacia papyrocarpa) open woodland in South Australia. Journal of Vegetation Science. 30 (4), 11, 2019.
28. ROSENTRETER R. Biocrust lichen and moss species most suitable for restoration projects. Restoration ecology. 28 (2), 67, 2020.

29. KAKEH J., GORJI M., MOHAMMADI M.H. MHBiological soil crusts determine soil properties and salt dynamics under arid climatic condition in Qara Qir, Iran. Science of the total environment. 732 (25), 139, 2020

30. WANG S.J., HUANG X.F., ZHOU Y.C. Soil organic carbon change relating to the prevention and control of rocky desertification in Guizhou Province. International Journal of Global Warming. 61 (15), 3, 2018.

31. QIN F.W., KANG B.Y., JIANG F.Y., LIU X.L., XU H.K., WEI X.T., SHAO X.Q. Effects of Biological Soil Crust Succession on Vegetation Structure and Soil Nutrients in Alpine Steppe. Ecology and Environment Sciences. 28 (6), 1100, 2019.

32. DU J., LI Y.X.,YANG X.X., LI Y.F., MA X.J. Effects of Biological Soil Crusts Types on Soil Physicochemical Properties in the Southeast Fringe of the Tengger Desert. Journal of Desert Research. 38 (1), 111, 2018.

33. MIRALLES ISABEL., DOMINGO FRANCISCO., GARCIA-CAMPOS., GIL-SOTRES. FERNANDO, CARMEN LEIROS. M., TRASAR-CEPEDA. CARMEN. Elena Biological and microbial activity in biological soil crusts from the Tabernas desert, a sub-arid zone in SE Spain. Soil Biology and Biochemistry. 55 (9), 113, 2012.

34. SONG G., LI X., HU R. Biological soil crusts determine the germination and growth of two exotic plants. Ecology and Evolution. 22 (7), 9441, 2017.

35. ZHAO C.L., YANG Y.S., WANG S.F., HILL ROBERT LEE., ZHANG P., BU C.F., ZHAO Y. Wind erosion prevention characteristics and key influencing factors of bryophytic soil crusts. Plant and Soil. 397 (10), 163, 2015.

36. WANG Y.L., LI X.R., ZHAO J.C., LIU L.C., YANG H.Y., ZHOU Y.Y. Population dynamics of Echinops gmelinii Turcz. at different successional stages of biological soil crusts in a temperate desert in China. Plant biology. 21 (6), 1140, 2019.

37. YING B., XIAO S.Z., XIONG K.N., CHENG Q.W., LUO J.S. Comparative studies of the distribution characteristics of rocky desertification and land use/land cover classes in typical areas of Guizhou province, China. Environmental earth sciences. 71 (2), 4631, 2014.

38. ANTONINKA, ANITA, FAIST, AKASHA, RODRIGUEZ-CABALLERO. EMILIO., YOUNG. KRISTINA E., CHAUDHARY. V. BALA., CONDON. LEA A., PYKE. DAVID A. Biological soil crusts in ecological restoration: emerging research and perspectives. Restoration Ecology, 28 (2), 3, 2020.

39. KLEINHESSELINK. ANDREW R., CUSHMAN. J. HALL. Effects of native bryophytes on exotic grass invasion across an environmental gradient. Ecosphere. 10 (6), 75, 2019. 